\title{
Evaluación nutricional del etiquetado de piezas de pollo
}

\author{
Nutritional evaluation of chicken parts labeling \\ Amador-Amador, S. ${ }^{a}$, Cornejo-Hernández, $F^{b}$, Fuentes-Hernández, A.L. ${ }^{c}$, Pineda-Juárez, $J^{d}{ }^{d}$, \\ Ariza-Ortega, J.A. ${ }^{e}$, Ramírez-Moreno, E. ${ }^{f}$
}

\begin{abstract}
:
Chicken meat is a source of high biological value protein, in addition to other macronutrients and micronutrients that are desirable for human consumption. Therefore, the objective of this work was to compare the nutritional composition and quality parameters in chicken pieces (leg and breast) marketed in supermarkets in Pachuca de Soto, Hidalgo. A compilation of nutritional information on the labeling of commercial chicken products was carried out using NMX-FF-080-2006, NOM-086-SSA1-1994 and Codex Alimentarious as a comparison analysis. Poultry derivatives are protein products and the specific breast with low fat content. However, the products evaluated did not meet these specifications according to the Codex Alimentarious, with few specific. Chicken meat is considered a low sodium product, however, one of the products evaluated, exceeds the limit stipulated by NOM-086-SSA1-1994 ( $\leq$ $140 \mathrm{mg}$ ). Most of the products evaluated in the Mexico Extra category, an exception of a product classified as Mexico 1. It is important to inform patients who suffer the nutritional symptoms and physical attributes of meat products for proper consumption.
\end{abstract}

Keywords:

Proteins, lipids, labelled, nutrients.

\section{Resumen:}

La carne de pollo es una fuente de proteína de alto valor biológico, además de otras macronutrientes y micronutrientes que son deseables para el consumo humano. Por lo anterior, el objetivo del presente trabajo fue comparar la composición nutrimental y los parámetros de calidad en piezas de pollo (pierna y pechuga) comercializado en supermercados de Pachuca de Soto, Hidalgo. Se realizó una recopilación la información nutrimental del etiquetado de productos de pollo comerciales tomando como estándares de comparación la NMX-FF-080-2006, la NOM-086-SSA1-1994 y el Codex Alimentarious. Los derivados avícolas son considerados productos proteicos y la pechuga en específico con bajo contenido de grasa. Sin embargo los productos evaluados no cumplieron con estas especificaciones de acuerdo al Codex Alimentarious (2019), con escasas excepciones. La carne de pollo es considerado un producto con bajo contenido de sodio, sin embargo, uno de los productos evaluados, sobrepaso el límite estipulado por la NOM-086SSA1-1994 ( $\leq$ a $140 \mathrm{mg}$ ). La mayoría de los productos evaluados presentaron la categoría México Extra, a excepción de un producto clasificado como México 1. Es importante dar a conocer a los consumidores los estándares nutricionales y atributos físicos de los productos cárnicos para un consumo adecuado.

\section{Palabras Clave:}

Proteínas, lípidos, etiquetado, nutientes

\footnotetext{
a Universidad Autónoma del Estado de Hidalgo, https://orcid.org/0000-0002-0604-2098, Email: san.1012@ hotmail.com

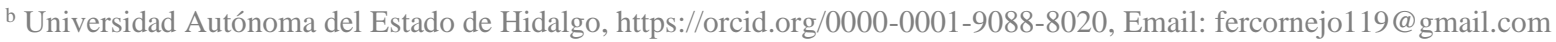

c Universidad Autónoma del Estado de Hidalgo, https://orcid.org/0000-0002-3590-7126, Email: alfh.97p@ gmail.com

d Universidad Autónoma del Estado de Hidalgo, Email: jepijuarz@ gmail.com

e Universidad Autónoma del Estado de Hidalgo, https://orcid.org/0000-0002-2163-4593, Email: jose190375@ @otmail.com

Autor de Correspondencia, Universidad Autónoma del Estado de Hidalgo, https://orcid.org/0000-0002-9928-8600, Email:
} esther_ramirez@uaeh.edu.mx 


\section{Introducción}

En México, el consumo de pollo se ha duplicado de 19942017, alcanzando un consumo aparente de $32.88 \mathrm{~kg}$ por habitante al año. ${ }^{1}$

Con respecto a su valor nutricional, la carne de pollo es una fuente de proteína de alto valor biológico, al contener una concentración importante de aminoácidos esenciales, como son lisina y niacina. Además, aporta minerales como: calcio, hierro, zinc, fósforo y potasio. ${ }^{2} \mathrm{El}$ contenido de grasa que presentan los productos es bajo caracterizado por ácidos grasos saturados, monoinsaturados y colesterol. ${ }^{3}$ En general, todos estos constituyentes lipídicos forman parte del tejido adiposo. Es importante mencionar que más del $70 \%$ del tejido adiposo es de fácil remoción, por lo que al eliminar la piel, se descarta la grasa que se encuentra unida. ${ }^{4}$

Por otro lado, de acuerdo a la NMX-FF-080-2006, el pollo se puede clasificar de acuerdo a los atributos que presenta como: México 2, México 1 y México Extra, siendo la última clasificación el pollo de mayor calidad, y debe presentar los siguientes:

- Una musculatura bien desarrollada, libre de deformidades que afecten la distribución normal de la carne de contornos redondeados.

- En cuanto a los restos de vísceras sólo se permiten riñón o restos del mismo en rabadilla.

- La apariencia de la piel debe de presentar uniformidad en el color sin importar si este es blanco o amarillo, no se permiten rasgaduras lineales que expongan la carne de la pieza, se permite la decoloración para el pollo pintado.

- Libre de hematomas (moretones).

- Tiene que ser libre de manchas de bilis.

- No debe presentar plumas, únicamente se aceptan filo plumas en alas.

- No debe presentar fracturas.

- Libre de mutilaciones.

Por lo anterior, el objetivo del presente trabajo fue comparar la composición nutrimental y los parámetros de calidad en piezas de pollo (pierna y pechuga) comercializado en supermercados de Pachuca de Soto, Hidalgo.

\section{Metodología}

Para realizar este estudio, se recopiló la información nutrimental del etiquetado de productos de pollo expendidos en supermercados, que se encuentran ubicados en la ciudad de Pachuca de Soto; Hidalgo, México. Los valores reportados en el etiquetado de proteína, grasas y sodio, se compararon con los parámetros establecidos por las normas mexicanas de productos avícolas carne de pollo de engorda en canal y en piezas según la NMX-FF-080-2006, la NOM-086SSA1-1994 y el Codex Alimentarios.

\section{Resultados y Discusión}

En la Tabla 1 se muestra la composición nutrimental de las diferentes piezas de pollo en marcas comerciales.

Según el Codex Alimentarious. ${ }^{5}$ la cantidad de proteína por cada $100 \mathrm{~g}$ de carne de pollo debe ser de $22.8 \mathrm{~g}$. La cantidad de proteína depende de la alimentación de crianza del pollo por lo que los valores pueden variar entre marcas comerciales analizadas. Las marcas evaluadas no cumplen los parámetros establecidos, ya que presentaron valores entre $7-18 \mathrm{~g} / 100 \mathrm{~g}$.

Tabla 1. Valores Nutrimentales de Piezas de pollo comercial en porción de $100 \mathrm{~g}$.

\begin{tabular}{|c|c|c|c|c|c|c|}
\hline & $\begin{array}{l}\text { Proteína } \\
\text { (g) }\end{array}$ & $\begin{array}{c}\text { Grasas } \\
\text { Totales } \\
(\mathrm{g})\end{array}$ & $\begin{array}{c}\text { Grasa } \\
\text { Saturada } \\
\text { (g) }\end{array}$ & $\begin{array}{l}\text { Hidratos } \\
\text { de } \\
\text { Carbono } \\
\text { (g) }\end{array}$ & Sodio mg & Kcal \\
\hline $\begin{array}{l}\text { Pierna de } \\
\text { pollo con } \\
\text { piel Pilgrim's }\end{array}$ & 18.05 & 8.33 & 2.57 & 2.9 & 49.32 & 158.57 \\
\hline $\begin{array}{l}\text { Pechuga sin } \\
\text { piel Bachoco }\end{array}$ & 12.47 & 0.2 & 0.8 & 0.8 & 195 & 52 \\
\hline $\begin{array}{l}\text { Filete de } \\
\text { pechuga } \\
\text { Bachoco }\end{array}$ & 10.16 & 0.48 & 0.14 & 2.27 & 9.94 & 54 \\
\hline $\begin{array}{l}\text { Pechuga } \\
\text { Pilgrim's }\end{array}$ & 18.05 & 8.33 & 2.57 & 2.9 & 49.32 & 158.77 \\
\hline $\begin{array}{l}\text { Pechuga } \\
\text { Practirico }\end{array}$ & --- & 1.8 & 0.5 & 0 & 175 & 99 \\
\hline $\begin{array}{c}\text { Pierna sin } \\
\text { piel baja en } \\
\text { grasa } \\
\text { Bachoco }\end{array}$ & 7.05 & 2.02 & 0.42 & 1.43 & 15.64 & 52.02 \\
\hline $\begin{array}{c}\text { filete de } \\
\text { pierna-muslo } \\
\text { Bachoco }\end{array}$ & 9.04 & 3.09 & 0.91 & 0.54 & 145 & 52.02 \\
\hline
\end{tabular}

La pechuga de pollo es una pieza del animal que tiene un bajo contenido de grasa. De acuerdo al Codex Alimentarious, ${ }^{5}$ indica que la cantidad de grasa por cada $100 \mathrm{~g}$ de carne de pollo es de $0.9 \mathrm{~g}$. La pechuga sin piel y el filete de pechuga de la marca Bachoco se encuentran dentro de lo indicado por la norma, y las otras marcas se encuentran por encima de los parámetros establecidos muy posiblemente por la piel y restos de grasa intramuscular que mantiene el producto.

El contenido de carbohidratos en estos productos es generalmente bajo, ya que durante el proceso de matanza de pollo se gasta toda la reserva de glucosa. ${ }^{6}$ Por lo tanto en estos productos los carbohidratos se encontraron en valores de 0 a $2.9 \mathrm{~g}$.

La carne de pollo es considerada como un producto bajo en sodio de acuerdo a la NOM-086-SSA1- 
1994 ( $\leq$ a $140 \mathrm{mg}),{ }^{7}$ excepto en la pechuga sin piel de la marca Bachoco que superó este valor.

Todas las muestras evaluadas estuvieron dentro de la categoría de México Extra, al presentar una buena calidad de acuerdo a los atributos evaluados indicando un pollo fuerte y de buen peso (buen tamaño, estructura integra, pechuga ancha y redondeada), de acuerdo a la NMX-FF-080-2006 ${ }^{8}$. La única excepción fue la marca Pilgrim's que presentó manchas de sangre visibles en el empaque por lo que se clasificó como México 1.

\section{Conclusiones}

Los derivados avícolas son considerados productos proteicos y la pechuga en específico con bajo contenido de grasa. Sin embargo los productos evaluados no cumplieron con estas especificaciones de acuerdo al Codex Alimentarious (2019), con escasas excepciones.

La carne de pollo es considerado un producto con bajo contenido de sodio, sin embargo, uno de los productos evaluados, sobrepaso el límite estipulado por la NOM-086-SSA1-1994 ( $\leq$ a $140 \mathrm{mg}$ ).

La mayoría de los productos evaluados presentaron la categoría México Extra, a excepción de un producto clasificado como México 1.

\section{Referencias}

[1] Unión Nacional de Avicultores. (2019). Situación de la avicultura mexicana. Consultado de: http://www.una.org.mx/index.php/component/content/article/15panorama/3-avicultura Acceso: 19 de agosto de 2019

[2] Gallinger, 1., C. 2015. Composición Química y mineral de la carne de pollo documento recuperado en:

https://www.engormix.com/avicultura/articulos/determinacioncomposicion-nutricional-carne-t32745.htm\#_=_Acceso: el 1 de septiembre de 2019

[3] Carbajal A, (2018). Departamento de Nutrición. Facultad de Farmacia. Universidad Complutense de Madrid Manual de nutrición y dietética https://www.ucm.es/nutricioncarbajal/

[4] Sanchez-Gurmaches J, Hung C-M, Guertin DA. 2016. Emerging complexities in adipocyte origins and identity. Trends in cell biology. $26: 5$

[5] Codex Alimentarious (2019). Composición de la carne. Departamento de Agricultura y Protección al Consumidor. Dirección: http://www.fao.org/ag/againfo/themes/es/meat/backgr_composition.ht ml Acceso: 20 de Agosto de 2019

[6] Forrest, J., Aberte, E., Hedrick, H., Judge, M., \& Merkel, R. (1975) Fundamentos de ciencia de la carne. En Capitulo 7 "Factores que influencian los cambios postmortales y las propiedades finales de la carne. España: Ed. Acribia. pp 135- 137.

[7] NOM-086-SSA1-1994. (1994). Bienes y servicios. Alimentos y bebidas no alcohólicas con modificaciones en su composición. Especificaciones Nutrimentales.

[8] NMX-FF-080-2006. (2006). Bienes y servicios. Huevos, sus productos y derivados. Disposiciones y especificaciones sanitarias. México: Secretaria de Salud. 